\title{
Catheter-Related Thrombosis: Risks, Diagnosis, and Management
}

\author{
Michael L. Linenberger, MD, Seattle, Washington
}

\author{
Key Words \\ Thrombosis, central venous catheter, deep vein thrombosis, pul- \\ monary embolism, anticoagulation
}

are needed to identify the safest and most effective anticoagulant agents, treatment durations, and alternative venous access strategies for cancer patients who develop catheter-associated thrombosis. (JNCCN 2006;4:889-901)

Implanted and external semipermanent central venous catheters (CVCs) are essential for optimal management of complicated patients with solid tumors and hematologic malignancies. Their usefulness for blood sampling, infusions, and, in some cases, apheresis procedures is counterbalanced by the fact that these devices are nonbiologic foreign bodies that can activate coagulation locally and interact physiologically with hereditary and acquired hypercoagulable conditions to induce thrombosis.

Among the general population, roughly $9 \%$ of first venous thromboembolic events are causally associated with a CVC or transvenous pacemaker, and recent CVC placement increases the risk for upper-extremity deep vein thrombosis (DVT) by 5- to 7-fold. ${ }^{1,2}$ Spontaneous upperextremity DVT is 2.6-to 8-fold more likely among patients with active cancer, ${ }^{3,4}$ and a CVC significantly augments that risk. ${ }^{4,5}$ The managing oncologist must be cognizant of this risk and that additional circumstances that further predispose to thrombosis may justify the use of prophylactic anticoagulation for selected patients. Moreover, because catheter-associated thromboembolic events are still relatively common among high-risk subgroups, the optimal approaches for diagnosis and management are important to understand.

\section{Device-Related Incidence and Risk Factors}

Central venous access devices that are designed for long-term use include surgically tunneled, externalized single or multiple lumen catheters, and fully implanted catheters that are connected to resealable diaphragm ports that are positioned under the skin of the chest or arm. 
Peripherally inserted central catheters (PICCs) are also commonly used for patients who require only temporary access (e.g., weeks as opposed to many months). Different models of each of these catheter types are manufactured with intraluminal pressure-sensitive valves that prevent passive blood reflux. Temporary or tunneled CVCs are also available with larger lumen diameters that accommodate the high flow rates necessary for leukapheresis (e.g., to collect peripheral blood stem cells) or other apheresis procedures. These double- or triple-lumen external devices are inserted into the internal jugular, subclavian, or femoral vein. Tunneled apheresis catheters that are used for stem cell collection are commonly retained throughout the course of hematopoietic stem cell transplant (HSCT), unless a complication necessitates removal.

\section{PICCs}

Thrombotic complications specifically associated with PICCs and implanted port systems have been characterized in retrospective and prospective cohort studies. Based on recent observations, occult PICC-related venous thrombosis is detected in 23\% to $39 \%$ of cancer patients undergoing surveillance venography, ${ }^{6,7}$ whereas symptomatic thromboembolism (manifested by pain, swelling, or erythema) or thrombotic occlusion requiring catheter removal occurs in only $3.4 \%$ to $3.9 \%$ of patients. ${ }^{8,9}$ Most symptomatic events with PICCs occur within the first 2 weeks of placement and involve the cephalic or basilic arm veins rather than the central vessels. Higher thrombotic risk is associated with larger lumen diameter and infusion of chemotherapy. ${ }^{8}$

\section{Central Port Catheters}

Clinically overt upper-extremity thrombosis occurs in $0 \%$ to $9 \%$ of cancer patients with port catheters that are implanted in the chest. ${ }^{10-16}$ By comparison, thrombotic complications are more common in arm ports, with incidence rates ranging from $2 \%$ to $30 \% .{ }^{10,11,14}$ As with PICCs, many of the events with arm ports involve the proximal arm veins rather than the central veins. Port-related DVT is predisposed by catheter tip malposition. ${ }^{12-14}$ Left-sided placement (compared with right) has been identified as a risk factor in some studies $^{14,15}$ but not in others. ${ }^{13,16}$ One prospective randomized clinical trial found no differences in the rates of overall thrombosis with central (chest) ports connected to valved lumens compared with port catheters with open lumens ( $4 \%$ vs. $7.3 \%) .{ }^{16}$

\section{External Tunneled Catheters}

Long-term, tunneled, external CVCs induce thrombosis at rates similar to implanted chest port catheters; however, the reported incidence varies based on the study population and diagnostic criteria. In the early 1990s, approximately 9\% of patients with hematologic malignancies undergoing HSCT developed symptomatic CVC-related thrombosis and up to $63 \%$ were found to have asymptomatic subclavian vein thrombi on venographic surveillence. ${ }^{16-19}$ More recent prospective and retrospective studies that included only cancer patients observed symptomatic thrombosis in $4.7 \%$ to $10 \%$ of adults ${ }^{20-22}$ and $2 \%$ to $2.5 \%$ of children with tunneled external CVCs. ${ }^{23,24}$ Incidence rates of asymptomatic clots ranged from $30 \%$ to $74 \% .{ }^{25,26}$ As with implanted ports, tunneled catheters with closed (valved) lumens offer no added protection from thrombotic complications when compared with open-lumen catheters. ${ }^{17}$ One patient subgroup that appears to be at greater risk with external catheters than with implanted ports is children with acute lymphoblastic leukemia (ALL). A 3.9-fold higher rate of thrombosis was observed among 49 children with ALL and external CVCs compared with 236 children with implanted ports. ${ }^{27}$

\section{General Incidence and Technical Risk Factors}

Recent prospective thromboprophylaxis trials that included patients with all types of catheters showed generally lower incidence rates of CVC-related thrombosis compared with earlier studies (see later discussion). This trend contradicts the higher annual percentages of venous or arterial thrombotic complications diagnosed among cancer patients in 2002 compared with $1995 .^{28}$ The reason for this discrepancy is not clear but may relate to avoidance or minimization of technical risk factors that predispose to CVC-associated thrombosis, including thrombogenic catheter material (e.g., polyethylene compared with polyurethane or silicone), ${ }^{29}$ larger catheter diameter or greater number of catheter lumens, ${ }^{8,17,20,22,24}$ catheter tip malposition, ${ }^{12-14,20,21,30}$ percutaneous insertion techniques (compared with cut-down), ${ }^{31}$ left-sided placement, ${ }^{14,15,31,32}$ or two or more insertion attempts (compared with one; see Table 1). ${ }^{33}$ A potential additional risk, at least in some adults with malignancies ${ }^{22}$ and children with ALL who receive asparaginase, ${ }^{31}$ but not in general medical or surgical patients, ${ }^{34}$ is the insertion of the CVC in the subclavian vein compared with the internal jugular vein. 
Catheter-Related Thrombosis

Table 1 Risk Factors Associated with Central Venous Catheter-Related Thromboembolism Among General Oncology Patients or Patient Subgroups

\section{Technical}

Thrombogenic catheter material

Larger catheter diameter or greater number of catheter lumens

Catheter tip malposition

Percutaneous insertion techniques (compared with cut-down)

Two or more insertion attempts

Prior CVC insertion

Left-sided placement

Subclavian vein insertion (compared with internal jugular)

\section{Patient and Vascular}

Catheter-associated infection

Fibrinous catheter lumen occlusion

Extrinsic vascular compression

Factor V G1691A (Leiden) mutation (and possibly other thrombophilias)

Prior venous thromboembolism

Ovarian cancer

\section{Treatment-Related}

L-asparaginase (during induction therapy for acute lymphoblastic leukemia)

Estrogen or progesterone agents

Recombinant human erythropoietin (with chemotherapy and radiation for cervical cancer)

Interleukin-2 (for melanoma or renal cell carcinoma)

Granulocyte-macrophage colony-stimulating factor (during peripheral blood stem cell mobilization and collection)

Thalidomide (in combination with corticosteroids or additional agents for myeloma)

Heparin (in the setting of heparin-induced thrombocytopenia)

\section{Patient and Treatment-Related Risks}

\section{Disease and Vascular Factors}

Cancer-related lower-extremity DVT and pulmonary embolism (PE) are strongly associated with specific malignant diagnoses, metastatic disease stage (compared with limited-stage disease), additional medical comorbidities, and active anticancer therapy. ${ }^{28,35,36}$ However, only a couple of potential disease-specific risk factors have been identified for CVC-related thrombosis. Two studies have reported statistically significant (5.6- and 4.8-fold) higher risks for catheter-related thrombosis in patients with ovarian cancer compared with other tumor types. ${ }^{14,33}$ However, only 14 patients with ovarian cancer were included in the retrospective study, ${ }^{14}$ and the more recent prospective trial ${ }^{33}$ was confounded by the fact that the women with ovarian cancer had undergone more venipunctures and chemotherapy than other patient groups. Enlarged cervical or mediastinal lymph nodes were associated with port-related thrombophlebitis in a study of patients with various solid tumors, suggesting that external vascular compression might be an independent risk factor. ${ }^{12}$

Prior CVC insertion was associated with a 3.8fold higher risk for catheter-related thrombosis in a recent prospective trial..$^{33}$ This relationship may be explained by the fact that $14 \%$ to $40 \%$ of children and adults with a prior CVC have central vein thrombosis or stenosis on follow-up imaging studies. ${ }^{37-39}$ The significance of a personal history of DVT is unclear. A study of 252 patients, including 136 with malignancies, who underwent prospective weekly Doppler imaging, showed a 2-fold relative risk for catheter-related DVT among those with a prior history of venous thrombosis. ${ }^{40}$ By comparison, no significant association was observed for venous thrombotic events, including 
a $1.5 \%$ rate of symptomatic catheter-related DVT, among 416 patients with hematologic malignancies. ${ }^{41}$

Recent studies have identified close associations between catheter-related infections and CVC thrombosis in cancer patients. One prospective trial that used ultrasound surveillance every 4 days found that early detection of thrombosis was $86 \%$ sensitive and $97 \%$ specific for an associated catheter-related bacterial line colonization, exit site infection, or bacteremia (positive and negative predictive values were 92\% and $93 \%$, respectively)..$^{42}$ In turn, the risk for developing clinically overt catheter-associated thrombosis was 18-fold greater among patients who were previously diagnosed with a CVC-related infection compared with those without a line infection. ${ }^{43}$ Septic thrombophlebitis is a serious complication of a catheter-related clot. In this regard, imaging with fluorine-18 fluorodeoxyglucose positron emission tomography can help in identifying deep vein septic thrombophlebitis in cancer patients with a CVC and recurrent bacteremia. ${ }^{44}$

\section{Thrombophilic Disorders in Children}

Hereditary and acquired thrombophilic conditions may contribute to the risks for catheter-related DVT among children with certain malignancies or undergoing certain therapies. A prospective study of 140 children, including 16 with leukemia, neuroblastoma, or Hodgkin lymphoma, showed that the factor $\mathrm{V}$ G1691A (Leiden) mutation, protein C deficiency, and elevated lipoprotein (a) had significant associations with clinically symptomatic CVC-related thrombosis. ${ }^{45}$ Two observational studies that included children with all types of hematologic malignancies and solid tumors also found frequent associations of symptomatic CVC-related thrombosis with heterozygous factor $\mathrm{V}$ Leiden mutation, elevated lipoprotein (a), or heterozygous prothrombin (factor II) G20210A mutation, with a high prevalence among children with ALL. ${ }^{46,47}$

A prospective German trial of children with ALL who were treated on a regimen that included Lasparaginase during induction therapy showed a strong positive correlation between thrombosis in the upper extremity or cerebral vessels and the presence of a CVC. ${ }^{48}$ Moreover, patients with 1 or more thrombophilic defects (mostly factor V or II mutations, elevated lipoprotein (a), and the TT 677 genotype of methylenetetrahydrofolate reductase [MTHFR]) had a significantly reduced thrombosis-free survival. ${ }^{48}$ By comparison, no thrombophilia-related risks were identified among children with ALL treated on a protocol that delayed the use of L-asparaginase until the intensification phase of treatment, ${ }^{49}$ or in 2 prospective cohort studies of children with ALL who underwent routine surveillance imaging to detect an asymptomatic clot. ${ }^{50,51}$ Notably, these latter 2 trials were underpowered to observe a potential significant association. An additional case-control study that included 10 children with ALL and 5 with nonHodgkin lymphoma found no association between CVC-related thrombosis and factor V Leiden mutation. ${ }^{52}$ Collectively, these data in children suggest that thrombophilic defects may play a role in CVC-related thrombosis in the context of additional treatment or disease-related prothrombotic risk factors.

\section{Thrombophilic Disorders in Adults}

Studies of various thrombophilic disorders in adults with malignancies have found either no, ${ }^{14,53,54}$ possible, ${ }^{40,55}$ or strong ${ }^{14,56-59}$ associations with catheter-related thrombosis. Some studies have described weak or possible associations for high factor VIII coagulant activity or anticardiolipin (or antiphospholipid) antibodies, ${ }^{40,50}$ but others have not. ${ }^{14,54}$ Among patients undergoing HSCT, factor V Leiden seems to be a strong risk factor, imparting roughly an 8-fold relative risk for thrombosis with tunneled, long-term $\mathrm{CVCs}^{56,58}$ and approximately a 5 -fold relative risk with nontunneled, externalized, shorter-term catheters. ${ }^{57}$ No associations were observed with factor V Leiden and clinical thrombosis in patients with various malignancies and either implanted ports, ${ }^{14}$ tunneled external catheters, ${ }^{54}$ or various CVCs. ${ }^{53}$ In contrast, a nested case-control study of women with locally advanced or metastatic breast cancer identified a 6 -fold relative risk for catheter-related thrombosis with factor $\mathrm{V}$ Leiden..$^{59}$

The prothrombin G20210A mutation was not an independent risk factor in a breast cancer cohort ${ }^{59}$ or in patients with various solid tumors. ${ }^{14}$ However, a 2.3-fold relative risk for asymptomatic thrombosis was attributable to the factor II G20210A mutation in a group of 252 patients, including 39 with solid tumors and 97 with hematologic malignancies. ${ }^{40}$ Hyperhomocysteinemia was associated with a 3.8-fold relative risk for catheterrelated clinical thrombosis in 1 study. ${ }^{14}$ Other trials have not systematically evaluated this abnormality and possible relationships with MTHFR gene polymorphisms. 
These observations in adults suggest that patients undergoing HSCT and women with advanced breast cancer have an increased risk for catheter-related thrombosis if they also carry the factor V Leiden mutation. Other patient subgroups with other primary thrombophilic disorders might also be at increased risk.

\section{Treatment-Related Factors}

Specific agents seem to increase the risk for CVC-related thrombosis under certain circumstances, including L-asparaginase during induction therapy for ALL; ${ }^{48,51,60}$ estrogen or progesterones in patients with hematologic malignancies; ${ }^{60}$ recombinant human erythropoietin in combination with chemotherapy and radiation in women with cervical cancer; ${ }^{61}$ interleukin2 in patients with melanoma or renal cell carcinoma (particularly those with associated bloodstream infection) $;^{62}$ granulocyte-macrophage colony-stimulating factor during peripheral blood stem cell mobilization and collection; ${ }^{63}$ and thalidomide in combination with corticosteroids or additional agents for myeloma (Table 1). ${ }^{64}$

In addition, heparin-induced thrombocytopenia (HIT) is a significant prothrombotic risk among patients with malignancy, ${ }^{65}$ and upper-extremity DVTs occur in up to $10 \%$ of patients with HIT and a CVC. ${ }^{66}$

\section{Diagnosis of Catheter-Related Thrombosis}

\section{Clinical Presentation}

Symptoms of CVC-related DVT include edema, pain, and erythema of the affected limb, and those associated with upper-extremity devices may include pain and swelling of the neck, supraclavicular area, or head. Chest catheters most commonly induce mural thrombi within the subclavian, axillary, and brachiocephalic veins; less than $15 \%$ affect the superior vena cava. ${ }^{32}$ Proximal arm vein thrombophlebitis is a more common complication with PICCs and peripheral ports. ${ }^{6-8,10,11,14}$ Less frequently, catheter-associated thrombosis presents with clinical signs and symptoms of PE. Symptomatic and asymptomatic PE accompany upper-extremity DVT in roughly $6 \%$ and $11 \%$ of patients, respectively. ${ }^{67}$

Asymptomatic thrombosis frequently presents with catheter occlusion, but device malfunction does not always correlate with thrombosis. Fibrin sheath formation and intraluminal fibrin or clot can either totally obstruct flow or cause a "ball-valve" effect. ${ }^{67}$ The latter problem was associated with a 2 -fold higher risk for subsequent CVC-related thrombosis among patients with a valved type of catheter. ${ }^{68}$ Similarly, catheter occlusion was noted to precede or accompany thrombosis in 12 of 50 patients with various types of CVCs. ${ }^{33}$ Despite these observations, 65\% of catheters with nonthrombotic mechanical problems (e.g., caused by malposition) also fail to withdraw blood; ${ }^{69}$ thus, catheter malfunction alone is a not a specific indicator of DVT.

\section{Imaging Modalities}

Contrast venography is the standard reference test for diagnosing DVT in the upper extremities. ${ }^{70}$ Venographic studies are often constrained, however, by technical and logistical issues, venous access limitations, and concerns of contrast toxicity. Therefore, noninvasive imaging modalities are most frequently used for patients with suspected catheter-associated thrombosis. Compression gray-scale ultrasonography is usually combined with pulsed Doppler signals (i.e., duplex ultrasound) or color Doppler flow imaging (i.e., color duplex ultrasonography) to evaluate for intravascular occlusions and blood flow abnormalities. These techniques can reliably evaluate the jugular, axillary, distal subclavian, and arm veins, but are less sensitive for the proximal subclavian vein, which is obscured by the clavicle. They cannot adequately visualize the brachiocephalic vein or superior vena cava.

A recent systematic review of 5 clinical trials that included 96 patients with CVC-associated thrombosis estimated that duplex ultrasound had an overall sensitivity of $56 \%$ to $100 \%$ and specificity of $94 \%$ to $100 \% .{ }^{71}$ A prospective study that included 18 patients with malignancy and CVC found that color duplex ultrasonography was $82 \%$ sensitive and $82 \%$ specific for venographically confirmed DVT. ${ }^{72}$ These data are similar to historical studies of this technique that reported $78 \%$ to $100 \%$ sensitivity and $88 \%$ to $100 \%$ specificity. ${ }^{70}$

Despite the reliability of noninvasive testing for most cases, some caveats remain. An isolated flow abnormality on color duplex ultrasonography is nonspecific and mandates contrast venographic assessment. ${ }^{72}$ In addition, no study has yet evaluated the safety of withholding anticoagulant therapy in patients with suspected catheter-associated DVT and a negative duplex ultrasound test. Therefore, contrast 
venography, serial follow-up duplex studies, or alternative imaging modality should be performed for these indeterminate cases. ${ }^{73,74}$

Spiral contrast computed tomography (CT) is useful for evaluating patients with suspected catheter-associated thrombosis involving the brachiocephalic vein or superior vena cava, and those with suspected $\mathrm{PE} .{ }^{70}$ However, prospective comparative studies of CT and contrast venography are lacking. Anatomic and technical constraints also limit the ability of contrast CT to accurately visualize more peripheral central vessels and arm veins. Magnetic resonance (MR) techniques, including contrast $\mathrm{MR}$ venogram, have also not been proven to be reliable alternatives to more conventional imaging methods for upper-limb DVT. ${ }^{70,75}$ Tortuous venous anatomy, catheter-related flow abnormalities, and motion artifact lead to signal dropout on MR imaging that confounds the detection of thrombosis in this setting.

\section{Prophylaxis of CVC-Related Thrombosis in Patients with Malignancy}

\section{Clinical Trial Data and Recommendations}

Recent evidence has clarified the role of routine anticoagulant prophylaxis for catheter-associated thrombosis. Table 2 summarizes the relevant retrospective and prospective studies that used specific prophylactic anticoagulant regimens exclusively among patients with malignancies and CVCs, along with defined clinical criteria or imaging modalities to diagnose suspected or occult thromboses.

Among early studies, the prospective, randomized, controlled trial by Bern et al. ${ }^{81}$ showed a significant benefit with "mini-dose" warfarin (i.e., $1 \mathrm{mg} / \mathrm{d}$ ). Similarly, dalteparin, at $2500 \mathrm{IU} / \mathrm{d}$, was effective in the study reported by Monreal et al..$^{82}$ (Table 2). Based on these observations, during the early 1990s through 2001 the consensus panels of the American College of Chest Physicians (ACCP) recommended that prophylactic anticoagulation be used for cancer patients with long-term indwelling CVCs. ${ }^{88}$ However, those recommendations were not widely followed in clinical practice. ${ }^{89}$

Results from more recent retrospective studies and randomized, prospective, placebo-controlled clinical trials (Table 2), in addition to observations from nonrandomized or mixed population studies that included adults ${ }^{33,40,41}$ or children ${ }^{90}$ with malignancies, have shown no benefit with prophylactic warfarin or low-molecular-weight heparins (LMWHs). Therefore, the latest ACCP consensus guidelines in 2004 recommended that routine thromboprophylaxis not be used for this indication. $^{91}$

\section{Additional Considerations}

The inherent limitations of available trial data, including small study populations, heterogenous disease groups, and different end points, and the lingering concerns about the relative frequency of asymptomatic clots and their pathophysiologic significance, have prompted recommendations for additional larger studies that focus on specific high-risk patient subgroups and the evaluation of newer antithrombotic agents. ${ }^{92-95}$ In addition, experts have suggested that thromboprophylaxis still be considered for patients believed to be at high risk for catheter-associated complications. ${ }^{92-95}$ Based on risk factors summarized in Table 1, candidate patients might include those with known thrombophilia, prior CVC insertion, prior catheter-associated or noncatheter DVT history, and anatomic or technical risk factors (e.g., bulky perivascular adenopathy, large catheter diameter, line malposition); those undergoing treatment with highly thrombogenic agents (e.g., thalidomide combination regimens); and possibly those with recurrent line-associated infections and occlusive device malfunctions.

Additional considerations derive from studies that observed a lower risk with prophylaxis for certain catheter types. For example, a retrospective investigation found that the rate of clinically overt catheter-related thrombotic complications (including asymptomatic clot detected after imaging for device malfunction) was significantly lower in patients with implanted chest port CVCs who were treated with either prophylactic nadroparin or warfarin $(1.3 \%$ vs. 33\% among those not treated with anticoagulation). ${ }^{14}$ Notably, this study showed no benefit from thromboprophylaxis among patients with arm port catheters.

In addition, a prospective, randomized, placebocontrolled trial of short-term, external, nontunneled double-lumen CVCs (duration $\leqslant 1$ month in $63 \%$ and $\leqslant 2$ months in $96 \%$ ) found significantly fewer clinical and asymptomatic thrombotic events among patients treated with a continuous infusion of unfractionated heparin $(100 \mathrm{IU} / \mathrm{kg} / \mathrm{d})$ compared with those treated with placebo $(1.5 \%$ vs. $12.6 \%) .{ }^{96}$ 
Catheter-Related Thrombosis

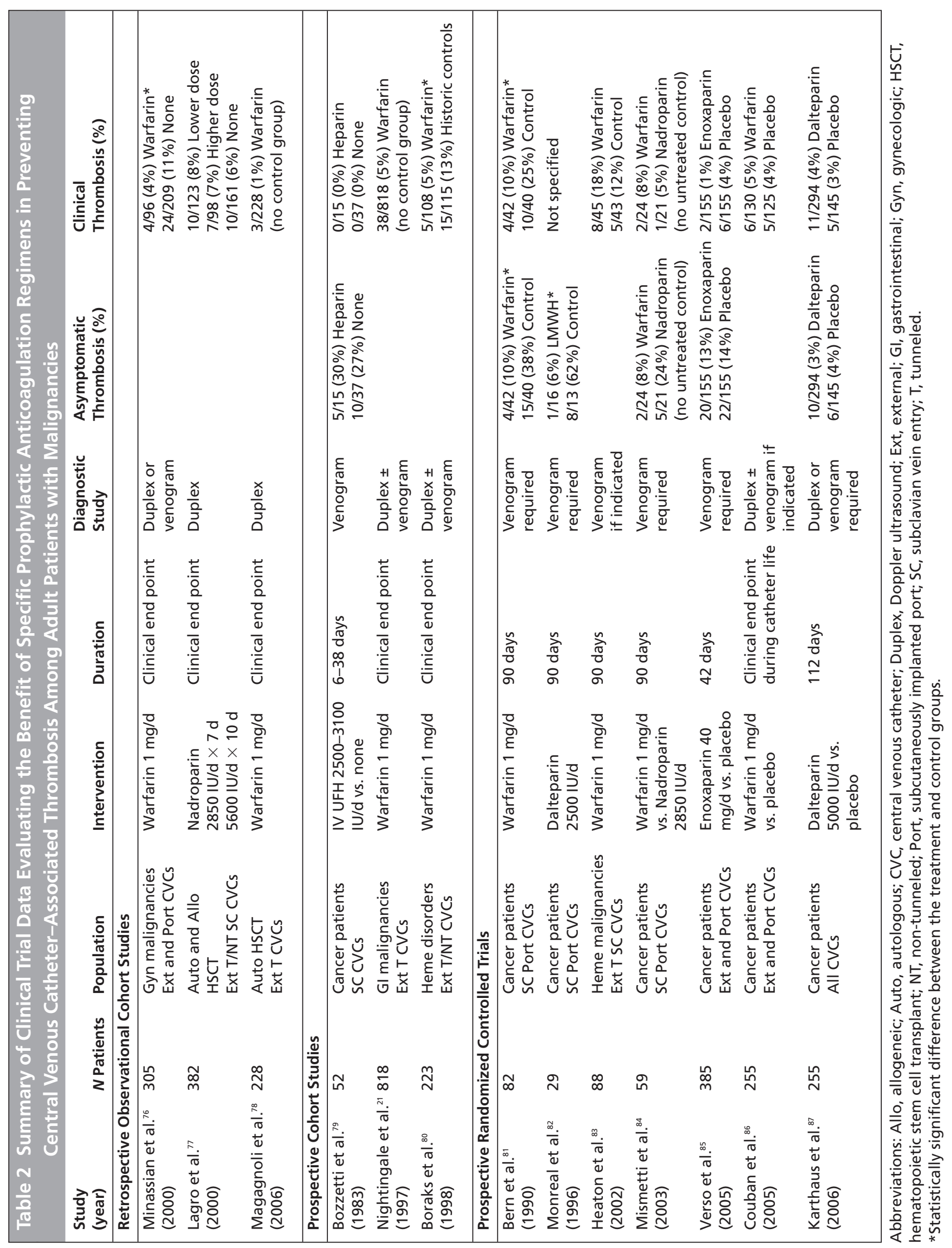




\section{Safety Issues}

Although the clinical indications for prophylactic use of warfarin or LMWH in higher-risk cancer patients with CVCs remain undefined, the use of these agents seems to be relatively safe. Recent randomized, prospective, placebo-controlled trials showed no significant differences among treated patients and controls in the rates of major bleeding complications (range, $0 \%$ to $0.7 \%$ and $0 \%$ to $2 \%$, respectively) or minor bleeding (range, $4 \%$ to $17 \%$ and $2 \%$ to $14 \%$, respectively). ${ }^{85-87}$ In addition, thrombocytopenia has not been associated with LMWH or unfractionated heparin in this setting..$^{84,85,87,96}$

Prophylactic warfarin at $1 \mathrm{mg} / \mathrm{d}$ can lead to significant elevations in the prothrombin time international normalized ratio (INR). The INR reached 1.5 or more in $20 \%$ to $51 \%$ of patients with gastrointestinal malignancies taking prophylactic warfarin during treatment with various 5 -fluorouracil-based regimens. ${ }^{97}$ Similarly, the INR reached more than 1.5 in $22 \%$ of patients with hematologic malignancies undergoing thromboprophylaxis. ${ }^{83}$ By comparison, only $2 \%$ of 130 patients with solid tumors and hematologic malignancies, including 14 who underwent HSCT, experienced an INR more than 2 over a median treatment period of 63 days. ${ }^{86}$ These data suggest that, if monitored appropriately, prophylaxis with LMWH or warfarin can be used safely for selected patients who are considered at high risk for CVC-associated thrombosis.

\section{Management of CVC-Related Thrombosis in Patients with Malignancy}

\section{Management of Luminal Occlusion and Fibrin Sheath}

Occlusion of the catheter tip by either intraluminal clot or external fibrin sheath deposition can cause complete obstruction of flow or a partial ball-valve effect in the absence of intravascular thrombosis. Device malfunctions of this type are common and, although not specific indicators of thrombosis, can precede or accompany catheter-associated DVT in a high proportion of cases. In the absence of clinical signs or symptoms of DVT or positional, mechanical, and precipitate causes for occlusion, catheter patency can usually be restored with local instillation of a thrombolytic agent.

Prospective, double-blind, placebo-controlled trials that included adult and pediatric cancer patients showed that catheter patency can be restored with intraluminal doses of alteplase, which is a recombinant tissue plasminogen activator ( $t$-PA), or recombinant urokinase in $85 \%$ and $54 \%$ of the cases, respectively, without hemorrhagic, embolic, or nonhematologic adverse events. ${ }^{98,99}$ These agents are effective with valved and open-lumen CVCs. Additional retrospective studies of alteplase in young children with cancer ${ }^{100}$ and prospective single-arm trials of reteplase, a newer recombinant $t$-PA variant, in pediatric ${ }^{101}$ and adult ${ }^{102}$ cancer patients showed success rates of $69 \%,{ }^{100}$ $80 \%,{ }^{101}$ and $95 \%,{ }^{102}$ respectively. Most cancer centers routinely use standard policies and procedure algorithms to treat asymptomatic CVC occlusions with thrombolytic agents, using the doses and intracatheter dwell times that these studies validated.

\section{Management of DVT and PE}

Radiographically confirmed DVT and PE require prompt intervention, regardless of whether the event is associated with catheter occlusion or signs and symptoms of venous obstruction. No prospective, randomized, controlled trial data are available to guide treatment recommendations. Management and treatment algorithms derive from retrospective and prospective observations of upper-extremity DVT in patients with or without cancer and with or without CVCs; anticoagulant approaches for lower-extremity DVT; and expert opinion. ${ }^{70,73,74,103}$ With centrally placed CVCs, the subclavian, axillary, internal jugular, and brachiocephalic veins are most commonly affected; however, clots can be found simultaneously in multiple regional vessels or in different segments of the same vein. ${ }^{104}$

The goal of treatment is to prevent or minimize the risks for clot extension, chronic post-thrombotic syndrome, PE, and recurrent DVT while safely maintaining venous access for ongoing antitumor therapy. The rate of post-thrombotic syndrome (i.e., chronic residual pain, swelling, skin discoloration, or ulceration) with catheter-associated DVT is poorly characterized, but ranges from $4 \%$ to $10 \%$ among cancer patients, ${ }^{33,105}$ and from $6 \%$ to $15 \%$ among unselected adults $^{3,106}$ and children ${ }^{107}$ with catheter-related or upper-extremity DVT. Similarly, the reported incidence of symptomatic PE with CVC-associated DVT varies widely, ranging from as low as $0 \%$ in some studies of cancer patients ${ }^{33,105}$ to $17 \%$ among unselected children $^{107}$ and adults ${ }^{67,108}$ with or without cancer. Notably, the incidence rates of PE with upper-extremity DVT 
are the same for clots involving the subclavian, axillary, or internal jugular veins. ${ }^{109}$

Initial management of children and adults with CVC-associated DVT or PE should include, unless contraindications exist, therapeutic anticoagulation with unfractionated heparin or LMWH for at least 5 to 7 days followed by transition to LMWH or warfarin. ${ }^{70,73,74,103,110}$ A published outpatient treatment regimen for uncomplicated patients with upper-extremity DVT not specifically catheter-associated used oncedaily dalteparin (dosed according to body weight) for 5 or more days, along with warfarin starting on day 1 and subsequent transition to warfarin alone for 3 months (maintaining the INR at 2-3). ${ }^{111}$ Among 46 patients undergoing this treatment in a prospective trial, only 1 developed recurrent DVT (2\%) and 1 suffered a major bleeding event (2\%). ${ }^{111}$ An alternative approach using initial LMWH followed by 6 months of oral anticoagulation therapy was similarly well tolerated by 36 patients with upper-extremity DVT, with no reported complications of PE, recurrent DVT, or post-thrombotic syndrome. ${ }^{112}$ Patients with increased risks for bleeding, such as those with chemotherapyinduced thrombocytopenia or a need for an invasive procedure, should be managed judiciously with LMWH $^{113}$ or unfractionated heparin. These agents are preferable because of their short half-lives and ability to reverse the effect, at least partially, with protamine.

The importance of initial anticoagulation with a CVC in place and the safety of catheter removal without anticoagulation have not been systematically addressed. One retrospective study of 170 patients with upper-extremity DVT that included 110 patients (65\%) with a CVC or pacemaker showed 1-month mortality rates of $10 \%$ among those who underwent anticoagulation compared with $24 \%$ among those who did not. ${ }^{106}$ Notably, although this survival difference supports anticoagulation, the deaths in this study were not caused by fatal PE.

In a retrospective review of treatment outcomes among oncology patients with catheter-associated thrombosis, 20 individuals treated with catheter removal alone experienced no episodes of recurrent DVT during the 2-week follow-up period. ${ }^{105}$ By comparison, removal and replacement of a new CVC, without anticoagulation, resulted in persistent thrombotic symptoms in 4 of 12 patients. ${ }^{105}$ In this same study, anticoagulation without catheter removal or anticoagulation with catheter replacement resulted in resolution of clinical signs and symptoms in 100\% of 39 and 13 patients, respectively. A recent prospective cohort study showed a similarly favorable outcome among 9 cancer patients who underwent anticoagulation but retained the catheter. ${ }^{33}$

The optimal duration of anticoagulation after catheter-associated thrombosis is also undefined. Prospective data from 1 thromboprophylaxis trial ${ }^{80}$ and 1 outcome study ${ }^{33}$ indicate that CVC removal and anticoagulation for 3 months ${ }^{80}$ or an unspecified time ${ }^{33}$ can effectively prevent symptomatic PE, recurrent DVT, and post-thrombotic syndrome.

Based on these observations, retaining the CVC seems acceptable if the thrombotic complication is not threatening to life or limb, if the line is functional and not infected, and if the patient can safely undergo anticoagulation. ${ }^{73,74,110}$ In this setting, or when the catheter is removed and replaced with another CVC, anticoagulation should be continued for the duration of the catheter or for as long as high-risk prothrombotic factors persist. If the catheter is removed, anticoagulation is recommended for 3 to 6 months. ${ }^{70,73,103}$ The duration may be shorter or longer, however, based on individual assessment of thrombosis severity, bleeding risk, and potential benefit. In patients with contraindications to anticoagulation, the catheter must be removed and the patient monitored for clot progression and PE. ${ }^{114}$ If the bleeding risk resolves, therapeutic anticoagulation should be carefully started and closely monitored. Patients with progressive thrombosis or PE are candidates for interventional techniques such as mechanical thrombectomy or placement of a permanent or retrievable filter in the superior vena cava. ${ }^{70,115,116}$

\section{Thrombolytic Therapy}

Thrombolytic therapy should be considered for extensive catheter-associated clot that threatens the viability or functional status of the extremity, or for PE associated with moderate-to-severe right ventricular dysfunction. ${ }^{70,73,74,103}$ Although catheter-directed infusion of the fibrinolytic agent may be appropriate for selected patients requiring limb salvage, systemic treatment is otherwise recommended. In all cases, bleeding risks and other potential contraindications must be carefully considered.

The overall benefit, safety, and outcomes of thrombolytic therapy in cancer patients are unknown. In a retrospective cohort analysis of 95 consecutive patients with subclavian-axillary vein thrombosis (including 
Linenberger

$15 \%$ with cancer and $15 \%$ with a CVC) who underwent either conventional anticoagulation or systemic urokinase, the thrombolysis group experienced a 60\% lower rate of persistent venous occlusion (assessed with ultrasound). However, $21 \%$ of those patients also experienced a bleeding complication, whereas none did in the anticoagulation cohort. ${ }^{117}$ More importantly, the rates of chronic, symptomatic post-thrombotic syndrome were no different between the 2 groups. ${ }^{117}$ Thus, no long-term advantage for thrombolytic therapy has been shown, and the bleeding risk is considerably higher than with anticoagulation. Notably, recent anecdotal experience suggests that systemic thrombolysis is a very useful adjunct for cancer patients with catheter-related septic thrombophlebitis, in addition to catheter removal and antimicrobials. ${ }^{118}$

\section{Conclusions}

Recent studies indicate that catheter-related symptomatic thromboembolic complications occur at a lower rate than previously observed among general oncology patients. However, specific factors have been identified that increase risk, particularly among certain patient subgroups. Patients who are believed to be at high risk may benefit from thromboprophylaxis, but optimal anticoagulant regimens for either prevention or treatment have not been determined. Properly designed, well-powered prospective trials are needed to address the safety and benefit of LMWH, warfarin, and newer antithrombotic agents among selected patient cohorts with malignancies.

\section{References}

1. Heit JA, Silverstein MD, Mohr DN, et al. Risk factors for deep vein thrombosis and pulmonary embolism: a population-based casecontrol study. Arch Intern Med 2000;160:809-815.

2. Joffe HV, Kucher N, Tapson VF, et al. Upper-extremity deep vein thrombosis: a prospective registry of 592 patients. Circulation 2004;110:1605-1611.

3. Prandoni P, Polistena P, Bernardi E, et al. Upper-extremity deep vein thrombosis. Risk factors, diagnosis, and complications. Arch Intern Med 1997; 157:57-62.

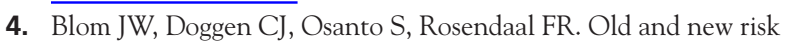
factors for upper extremity deep venous thrombosis. J Thromb Haemost 2005;3:2471-2478.

5. Giess CS, Thaler H, Bach AM, Hann LE. Clinical experience with upper extremity venous sonography in a high-risk cancer population. J Ultrasound Med 2002;21:1365-1370.

6. Allen AW, Megargell JL, Brown DB, et al. Venous thrombosis associated with the placement of peripherally inserted central catheters. J Vasc Interv Radiol 2000;11:1309-1314.
7. Abdullah BJ, Mohammad N, Sangkar JV, et al. Incidence of upper limb venous thrombosis associated with peripherally inserted central catheters (PICC). Br J Radiol 2005;78:596-600.

8. Grove JR, Pevec WC. Venous thrombosis related to peripherally inserted central catheters. J Vasc Interv Radiol 2000;11:837-840.

9. Walshe LJ, Malak SF, Eagan J, Sepkowitz KA. Complication rates among cancer patients with peripherally inserted central catheters. J Clin Oncol 2002;20:3276-3281.

10. Schwarz RE, Groeger JS, Coit DG. Subcutaneously implanted central venous access devices in cancer patients: a prospective analysis. Cancer 1997;79:1635-1640.

11. Kuriakose P, Colon-Otero G, Paz-Fumagalli R. Risk of deep venous thrombosis associated with chest versus arm central venous subcutaneous port catheters: a 5 -year single-institution retrospective study. J Vasc Interv Radiol 2002;13:179-184.

12. Labourey JL, Lacroix P, Genet $\mathrm{D}$, et al. Thrombotic complications of implanted central venous access devices: prospective evaluation. Bull Cancer 2004;91:431-436.

13. Luciani $A$, Clement $\mathrm{O}$, Halimi $\mathrm{P}$, et al. Catheter-related upper extremity deep venous thrombosis in cancer patients: a prospective study based on Doppler US. Radiology 2001;220:655-660.

14. Tesselaar MET, Ouwerkerk J, Nooy MA, et al. Risk factors for catheter-related thrombosis in cancer patients. Eur J Cancer 2004:40:2253-2259.

15. Puel V, Caudry M, Le Metayer P, et al. Superior vena cava thrombosis related to catheter malposition in cancer chemotherapy given through implanted ports. Cancer 1993;72:2248-2252.

16. Biffi R, De Braud F, Orsi F, et al. A randomized, prospective trial of central venous ports connected to standard open-ended or Groshong catheters in adult oncology patients. Cancer 2001;92:1204-1212.

17. Haire WD, Lieberman RP, Lund GB, et al. Thrombotic complications of silicone rubber catheters during autologous marrow and peripheral stem cell transplantation: prospective comparison of Hickman and Groshong catheters. Bone Marrow Transplant 1991;7:57-59.

18. Haire WD, Lieberman RP, Edney J, et al. Hickman catheter-induced thoracic vein thrombosis. Frequency and long-term sequelae in patients receiving high-dose chemotherapy and marrow transplantation. Cancer 1990;66:900-908.

19. Conlan MG, Haire WD, Lieberman RP, et al. Catheter-related thrombosis in patients with refractory lymphoma undergoing autologous stem cell transplantation. Bone Marrow Transplant 1991;7:235-240.

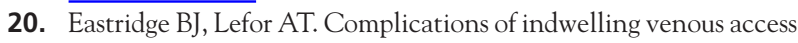
devices in cancer patients. J Clin Oncol 1995;13:233-238.

21. Nightingale CE, Norman A, Cunningham D, et al. A prospective analysis of 949 long-term central venous access catheters for ambulatory chemotherapy in patients with gastrointestinal malignancy. Eur J Cancer 1997;33:398-403.

22. Trerotola SO, Kuhn-Fulton J, Johnson MS, et al. Tunneled infusion catheters: increased incidence of symptomatic venous thrombosis after subclavian versus internal jugular venous access. Radiology 2000;217:89-93.

23. Molinari AC, Castagnola E, Mazzola C, et al. Thromboembolic complications related to indwelling central venous catheters in children with oncological/haematological diseases: a retrospective study of 362 catheters. Support Care Cancer 2001;9:539-544.

24. Fratino G, Molinari A C, Parodi S, et al. Central venous catheterrelated complications in children with oncological/hematological diseases: an observational study of 418 devices. Ann Oncol 2005; 16:648-654. 
Catheter-Related Thrombosis

25. Horne MK III, May DJ, Alexander HR, et al. Venographic surveillance of tunneled venous access devices in adult oncology patients. Ann Surg Oncol 1995;2:174-178.

26. Barzaghi A, Dell'Oto M, Rovelli A, et al. Central venous catheter clots: incidence, clinical significance and catheter care in patients with hematologic malignanices. Pediatr Hematol Oncol 1995;12: 243-250.

27. McLean TW, Fisher CJ, Snively BM, Chauvenet AR. Central venous lines in children with lesser risk acute lymphoblastic leukemia: optimal type and timing of placement. J Clin Oncol 2005;23: 3024-3029.

28. Khorana AA, Francis CW, Culakova E, et al. Thromboembolism in hospitalized neutropenic cancer patients. J Clin Oncol 2006;24: 484-490.

29. Monreal M, Raventos A, Lerma R, et al. Pulmonary embolism in patients with upper extremity DVT associated to venous central lines - a prospective study. Thromb Haemost 1994;72:548-550.

30. Schwarz RE, Coit DG, Groeger JS. Transcutaneously tunneled central venous lines in cancer patients: an analysis of device-related morbidity factors based on prospective data collection. Ann Surg Oncol 2000;7:441-449.

31. Male $C$, Chait $P$, Andrew $M$, et al. Central venous line-related thrombosis in children: association with central venous line location and insertion technique. Blood 2003;101:4273-4278.

32. De Cicco M, Matovic M, Balestreri L, et al. Central venous thrombosis: an early and frequent complication in cancer patients bearing long-term silastic catheter. A prospective study. Thromb Res 1997;86:101-113.

33. Lee AY, Levine MN, Butler G, et al. Incidence, risk factors, and outcomes of catheter-related thrombosis in adult patients with cancer. J Clin Oncol 2006;24:1404-1408.

34. Ruesch S, Walder B, Tramer MR. Complications of central venous catheters: internal jugular versus subclavian access-a systematic review. Crit Care Med 2002;30:454-460.

35. Blom JW, Doggen CJM, Osanto S, Rosendaal FR. Malignancies, prothrombotic mutations, and the risk of venous thrombosis. JAMA 2005;293:715-722.

36. Chew HK, Wun T, Harvey D, et al. Incidence of venous thromboembolism and its effect on survival among patients with common cancers. Arch Intern Med 2006;166:458-464.

37. Haire WD, Lynch TG, Lieberman RP, Edney JA. Duplex scans before subclavian vein catheterization predict unsuccessful catheter placement. Arch Surg 1992;127:229-230.

38. Gupta H, Araki Y, Davidoff AM, et al. Evaluation of pediatric oncology patients with previous multiple central catheters for vascular access: is Doppler ultrasound needed? Pediatr Blood Cancer 2006; Apr 26:Epub ahead of print.

39. Kraybill WG, Allen BT. Preoperative duplex venous imaging in the assessment of patients with venous access. J Surg Oncol 1993;52: 244-248.

40. van Rooden CJ, Rosendaal FR, Meinders AE, et al. The contribution of factor $\mathrm{V}$ Leiden and prothrombin G20210A mutation to the risk of central venous catheter-related thrombosis. Haematologica 2004;89:201-206.

41. Cortelezzi $\mathrm{A}$, Moia $\mathrm{M}$, Falanga $\mathrm{A}$, et al. Incidence of thrombotic complications in patients with haematological malignancies with central venous catheters: a prospective multicentre study. Br J Haematol 2005;129:811-817.

42. Lordick F, Hentrich $M$, Decker $T$, et al. Ultrasound screening for internal jugular vein thrombosis aids the detection of central venous catheter-related infections in patients with haemato-oncological diseases: a prospective observational study. $\mathrm{Br} J$ Haematol 2003;120: 1073-1078.

43. van Rooden CJ, Schippers EF, Barge RMY, et al. Infectious complications of central venous catheters increase the risk of catheterrelated thrombosis in hematology patients: a prospective study. J Clin Oncol 2005;23:2655-2660.

44. Miceli M, Atoui R, Walker R, et al. Diagnosis of deep septic thrombophlebitis in cancer patients by fluorine-18 fluorodeoxyglucose positron emission tomography scanning: a preliminary report. J Clin Oncol 2004:22:1949-1956.

45. Nowak-Gottl U, Dubbers A, Kececioglu D, et al. Factor V Leiden, protein $\mathrm{C}$, and lipoprotein (a) in catheter-related thrombosis in childhood: a prospective study. J Pediatr 1997;131:608-612.

46. Knofler R, Siegert E, Lauterbach I, et al. Clinical importance of prothrombotic risk factors in pediatric patients with malignancyimpact of central venous lines. Eur J Pediatr 1999;158(suppl 3): S147-S150.

47. Wermes C, von Depka Prondzinski M, Lichtinghagen R, et al. Clinical relevance of genetic risk factors for thrombosis in paediatric oncology patients with central venous catheters. Eur J Pediatr 1999;158(suppl 3):S143-S146.

48. Nowak-Gottl U, Wermes C, Junker R, et al. Prospective evaluation of the thrombotic risk in children with acute lymphoblastic leukemia carrying the MTHFR TT 677 genotype, the prothrombin G20210A variant, and further prothrombotic risk factors. Blood 1999;93: 1595-1599.

49. Mauz-Korholz C, Junker R, Gobel U, Nowak-Gottl U. Prothrombotic risk factors in children with acute lymphoblastic leukemia treated with delayed E. coli asparaginase (COALL-92 and 97 protocols). Thromb Haemost 2000;83:840-843.

50. Ruud E, Holmstrom H, Natvig S, Wesenberg F. Prevalence of thrombophilia and central venous catheter-associated neck vein thrombosis in 41 children with cancer-a prospective study. Med Pediatr Oncol 2002;38:405-410.

51. Mitchell LG, Andrew $M$, Hanna K, et al. A prospective cohort study determining the prevalence of thrombotic events in children with acute lymphoblastic leukemia and a central venous line who are treated with L-asparaginase: results of the Prophylactic Antithrombin Replacement in Kids with Acute Lymphoblastic Leukemia Treated with Asparaginase (PARKAA) Study. Cancer 2003;97:508-516.

52. Sifontes MT, Nuss R, Hunger SP, et al. The factor V Leiden mutation in children with cancer and thrombosis. $\mathrm{Br} \mathrm{J}$ Haematol 1997;96:484-489.

53. Riordan M, Weiden PL. Factor V Leiden mutation does not account for central venous catheter-related thrombosis. Am J Hematol 1998;58:150-152.

54. Ratcliffe $M$, Broadfoot $C$, Davidson $M$, et al. Thrombosis, markers of thrombotic risk, indwelling central venous catheters and antithrombotic prophylaxis using low-dose warfarin in subjects with malignant disease. Clin Lab Haematol 1999;21:353-357.

55. Ozguroglu M, Arun B, Erzin Y, et al. Serum cardiolipin antibodies in cancer patients with thromboembolic events. Clin Appl Thromb Hemost 1999;5:181-184.

56. Fijnheer R, Paijmans B, Verdonck LF, et al. Factor V Leiden in central venous catheter-associated thrombosis. $\mathrm{Br} \mathrm{J} \mathrm{Haematol}$ 2002;118:267-270.

57. Abdelkefi A, Ben Romdhane N, Kriaa A, et al. Prevalence of inherited prothrombotic abnormalities and central venous catheterrelated thrombosis in haematopoietic stem cell transplants recipients. Bone Marrow Transplant 2005;36:885-889. 
Linenberger

58. Jansen FH, van der Straaten HM, Roest M, et al. Elevated levels of D-dimer and fragment $1+2$ upon central venous catheter insertion and factor $\mathrm{V}$ Leiden predict subclavian vein thrombosis. Haematologica 2005;90:499-504.

59. Mandala M, Curigliano G, Bucciarelli P, et al. Factor V Leiden and G20210A prothrombin mutation and the risk of subclavian vein thrombosis in patients with breast cancer and a central venous catheter. Ann Oncol 2004;15:590-593.

60. Cortelezzia A, Fracchiolla NS, Maisonneuve P, et al. Central venous catheter-related complications in patients with hematological malignancies: a retrospective analysis of risk factors and prophylactic measures. Leuk Lymphoma 2003;44:1495-1501.

61. Wun T, Law L, Harvey D, et al. Increased incidence of symptomatic venous thrombosis in patients with cervical carcinoma treated with concurrent chemotherapy, radiation, and erythropoietin. Cancer 2003;98:1514-1520.

62. Eastman ME, Khorsand M, Maki DG, et al. Central venous device-related infection and thrombosis in patients treated with moderate dose continuous-infusion interleukin-2. Cancer 2001; 91:806-814.

63. Stephens LC, Haire WD, Schmit-Pokorny K, et al. Granulocyte macrophage colony stimulating factor: high incidence of apheresis catheter thrombosis during peripheral stem cell collection. Bone Marrow Transplant 1993;11:51-54.

64. Rajkumar SV. Thalidomide therapy and deep venous thrombosis in multiple myeloma. Mayo Clin Proc 2005;80:1549-1551.

65. Opatrny L, Warner MN. Risk of thrombosis in patients with malignancy and heparin-induced thrombocytopenia. Am J Hematol 2004;76:240-244.

66. Hong AP, Cook DJ, Sigouin CS, Warkentin TE. Central venous catheters and upper-extremity deep-vein thrombosis complicating immune heparin-induced thrombocytopenia. Blood 2003;101: 3049-3051.

67. Kuter DJ. Thrombotic complications of central venous catheters in cancer patients. Oncologist 2004;9:207-216.

68. Tolar B, Gould JR. The prognostic significance of the ball-valve effect in Groshong catheters. Support Care Cancer 1996;4:34-38.

69. Stephens LC, Haire WD, Kotulak GD. Are clinical signs accurate indicators of the cause of central venous catheter occlusion? JPEN J Parenter Enteral Nutr 1995;19:75-79.

70. Baarslag HJ, Koopman MM, Reekers JA, van Beek EJ. Diagnosis and management of deep vein thrombosis of the upper extremity: a review. Eur Radiol 2004;14:1263-1274.

71. Mustafa BO, Rathbun SW, Whitsett TL, Raskob GE. Sensitivity and specificity of ultrasonography in the diagnosis of upper extremity deep vein thrombosis: a systematic review. Arch Intern Med 2002;162:401-404.

72. Baarslag HJ, van Beek EJ, Koopman MM, Reekers JA. Prospective study of color duplex ultrasonography compared with contrast venography in patients suspected of having deep venous thrombosis of the upper extremities. Ann Intern Med 2002;136:865-872.

73. Verso M, Agnelli G. Venous thromboembolism associated with long-term use of central venous catheters in cancer patients. J Clin Oncol 2003;21:3665-3675.

74. van Rooden CJ, Tesselaar ME, Osanto S, et al. Deep vein thrombosis associated with central venous catheters-a review. JThromb Haemost 2005;3:2409-2419.

75. Baarslag HJ, van Beek EJ, Reekers JA. Magnetic resonance venography in consecutive patients with suspected deep vein thrombosis of the upper extremity: initial experience. Acta Radiol 2004;45: $38-43$.
76. Minassian VA, Sood AK, Lowe P, et al. Longterm central venous access in gynecologic cancer patients. J Am Coll Surg 2000;191: 403-409.

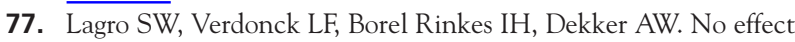
of nadroparin prophylaxis in the prevention of central venous catheter (CVC)-associated thrombosis in bone marrow transplant recipients. Bone Marrow Transplant 2000;26:1103-1106.

78. Magagnoli M, Masci G, Castagna L, et al. Prophylaxis of central venous catheter-related thrombosis with minidose warfarin in patients treated with high-dose chemotherapy and peripheral-blood stem-cell transplantation: retrospective analysis of 228 cancer patients. Am J Hematol 2006;81:1-4.

79. Bozzetti F, Scarpa D, Terno G, et al. Subclavian venous thrombosis due to indwelling catheters: a prospective study on 52 patients. JPEN J Parenter Enteral Nutr 1983;7:560-562.

80. Boraks P, Seale J, Price J, et al. Prevention of central venous catheter associated thrombosis using minidose warfarin in patients with haematological malignancies. Br J Haematol 1998;101:483-486.

81. Bern MM, Lokich JJ, Wallach SR, et al. Very low doses of warfarin can prevent thrombosis in central venous catheters. A randomized prospective trial. Ann Intern Med 1990;112:423-428.

82. Monreal M, Alastrue A, Rull M, et al. Upper extremity deep venous thrombosis in cancer patients with venous access devicesprophylaxis with a low molecular weight heparin (Fragmin). Thromb Haemost 1996;75:251-253.

83. Heaton DC, Han DY, Inder A. Minidose ( $1 \mathrm{mg})$ warfarin as prophylaxis for central vein catheter thrombosis. Intern Med J 2002;32:84-88.

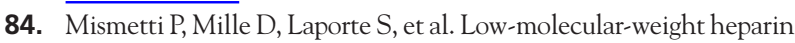
(nadroparin) and very low doses of warfarin in the prevention of upper extremity thrombosis in cancer patients with indwelling long-term central venous catheters: a pilot randomized trial. Haematologica 2003;88:67-73.

85. Verso M, Agnelli G, Bertoglio S, et al. Enoxaparin for the prevention of venous thromboembolism associated with central vein catheter: a double-blind, placebo-controlled, randomized study in cancer patients. J Clin Oncol 2005;23:4057-4062.

86. Couban S, Goodyear M, Burnell M, et al. Randomized placebo-controlled study of low-dose warfarin for the prevention of central venous catheter-associated thrombosis in patients with cancer. J Clin Oncol 2005;23:4063-4069.

87. Karthaus M, Kretzschmar A, Kroning H, et al. Dalteparin for prevention of catheter-related complications in cancer patients with central venous catheters: final results of a double-blind, placebocontrolled phase III trial. Ann Oncol 2006;17:289-296.

88. Geerts WH, Heit JA, Clagett GP, et al. Prevention of venous thromboembolism. Chest 2001;119(suppl 1):132S-175S.

89. Carr KM, Rabinowitz I. Physician compliance with warfarin prophylaxis for central venous catheters in patients with solid tumors. J Clin Oncol 2000;18:3665-3667.

90. Massicotte P, Julian JA, Gent M, et al. An open-label randomized controlled trial of low molecular weight heparin for the prevention of central venous line-related thrombotic complications in children: the PROTEKT trial. Thromb Res 2003;109:101-108.

91. Geerts W, Pineo GF, Heit JA, et al. Prevention of venous thromboembolism. The Seventh ACCP Conference on Antithrombotic and Thrombolytic Therapy. Chest 2004;126(suppl 3):338S-400S.

92. Cunningham MS, White B, Hollywood D, O'Donnell J. Primary thromboprophylaxis for cancer patients with central venous catheters-a reappraisal of the evidence. Br J Cancer 2006;94: 189-194. 
Catheter-Related Thrombosis

93. Huisman MV. Is antithrombotic prophylaxis required in cancer patients with central venous catheters? Yes for special patient groups. J Thromb Haemost 2006;4:10-13.

94. Agnelli $G$, Verso M. Is antithrombotic prophylaxis required in cancer patients with central venous catheters? No. J Thromb Haemost 2006;4:14-15.

95. Levine M. Is antithrombotic prophylaxis required in cancer patients with central venous catheters? Still an open question. J Thromb Haemost 2006;4:16-18.

96. Abdelkefi A, Ben Othman T, Kammoun L, et al. Prevention of central venous line-related thrombosis by continuous infusion of lowdose unfractionated heparin, in patients with haemato-oncological disease. A randomized controlled trial. Thromb Haemost 2004;92:654-661.

97. Magagnoli M, Masci G, Castagna L, et al. High incidence of INR alteration in gastrointestinal cancer patients treated with minidose warfarin and 5-fluorouracil-based regimens. Ann Oncol 2006;17:174-176.

98. Semba CP, Deitcher SR, Li X, et al. Treatment of occluded central venous catheters with alteplase: results in 1,064 patients. J Vasc Interv Radiol 2002;13:1199-1205.

99. Haire WD, Deitcher SR, Mullane KM, et al. Recombinant urokinase for restoration of patency in occluded central venous access devices. A double-blind, placebo-controlled trial. Thromb Haemost 2004;92:575-582.

100. Chesler L, Feusner JH. Use of tissue plasminogen activator (rt-PA) in young children with cancer and dysfunctional central venous catheters. J Pediatr Hematol Oncol 2002;24:653-656.

101. Terrill KR, Lemons RS, Goldsby RE. Safety, dose, and timing of reteplase in treating occluded central venous catheters in children with cancer. J Pediatr Hematol Oncol 2003;25:864-867.

102. Liu CY, Jain V, Shields AF, Heilbrun LK. Efficacy and safety of reteplase for central venous catheter occlusion in patients with cancer. J Vasc Interv Radiol 2004;15:39-44.

103. Buller HR, Agnelli G, Hull RD, et al. Antithrombotic therapy for venous thromboembolic disease: the Seventh ACCP Conference on Antithrombotic and Thrombolytic Therapy. Chest 2004; 126(suppl 3):401S-428S.

104. Schmittling ZC, McLafferty RB, Bohannon WT, et al. Characterization and probability of upper extremity deep venous thrombosis. Ann Vasc Surg 2004;18:552-557.

105. Frank DA, Meuse J, Hirsch D, et al. The treatment and outcome of cancer patients with thromboses on central venous catheters. J Thromb Thrombolysis 2000;10:271-275.
106. Hingorani A, Ascher E, Lorenson E et al. Upper extremity deep venous thrombosis and its impact on morbidity and mortality rates in a hospital-based population. J Vasc Surg 1997;26:853-860.

107. Monagle $\mathrm{P}$, Adams $\mathrm{M}$, Mahoney $\mathrm{M}$, et al. Outcome of pediatric thromboembolic disease: a report from the Canadian Childhood Thrombophilia Registry. Pediatr Res 2000;47:763-766.

108. Kooij JD, van der Zant FM, van Beek EJ, Reekers JA. Pulmonary embolism in deep venous thrombosis of the upper extremity: more often in catheter-related thrombosis. Neth J Med 1997;50: 238-242.

109. Ascher E, Salles-Cunha S, Hingorani A. Morbidity and mortality associated with internal jugular vein thromboses. Vasc Endovascular Surg 2005;39:335-339.

110. Bajzar L, Chan AK, Massicotte MP, Mitchell LG. Thrombosis in children with malignancy. Curr Opin Pediatr 2006;18:1-9.

111. Savage KJ, Wells PS, Schulz V, et al. Outpatient use of low molecular weight heparin (Dalteparin) for the treatment of deep vein thrombosis of the upper extremity. Thromb Haemost 1999;82: 1008-1010.

112. Karabay O, Yetkin U, Onol H. Upper extremity deep vein thrombosis: clinical and treatment characteristics. J Int Med Res 2004;32:429-435.

113. Herishanu Y, Misgav M, Kirgner I, et al. Enoxaparin can be used safely in patients with severe thrombocytopenia due to intensive chemotherapy regimens. Leuk Lymphoma 2004;45: 1407-1411.

114. Levine MN, Raskob G, Beyth RJ, et al. Hemorrhagic complications of anticoagulant treatment: the Seventh ACCP Conference on Antithrombotic and Thrombolytic Therapy. Chest 2004;126 (suppl 3):287S-310S.

115. Ascher E, Hingorani A, Tsemekhin B, et al. Lessons learned from a 6 -year clinical experience with superior vena cava Greenfield filters. J Vasc Surg 2000;32:881-887.

116. Nadkarni S, Macdonald S, Cleveland TJ, Gaines PA. Placement of a retrievable Gunther Tulip filter in the superior vena cava for upper extremity deep venous thrombosis. Cardiovasc Intervent Radiol 2002;25:524-526.

117. Sabeti S, Schillinger M, Mlekusch W, et al. Treatment of subclavian-axillary vein thrombosis: long-term outcome of anticoagulation versus systemic thrombolysis. Thromb Res 2002;108:279-285.

118. Volkow P, Cornejo-Juarez P, Arizpe-Bravo AB, et al. Catheter-related septic thrombophlebitis of the great central veins successfully treated with low-dose streptokinase thrombolysis and antimicrobials. Thromb J 2005;3:11. 